\title{
Erosividade das chuvas em trecho do médio curso da Bacia do rio Poti, Nordeste do Estado do Piauí
}

Erosivity (R) stretch of the middle course of the river basin Poti, the State of Piauí Northeast

CERQUEIRA $^{1}$, K. F.; SANTOS ${ }^{2}$, F. A.; AQUINO ${ }^{3}$, C. M. S. karolinyfoncer@gmail.com

\section{Resumo}

A constante exploração humana em territórios naturalmente frágeis, a exemplo do trecho do médio curso da Bacia do rio Poti, remete a necessidade de determinação do potencial de Erosividade das chuvas (R). Para isso, foram utilizados dados de precipitação de 13 (treze) estações pluviométricas da Superintendência do Desenvolvimento do Nordeste (SUDENE). Os dados tiveram suas falhas corrigidas conforme Método de Ponderação Regional, manuseados e refinados via pacote de programas USUAIS. Foram identificadas e especializadas 05 (cinco) classes de Erosividade das chuvas para a área. A interpretação dos dados demonstrou que a área apresenta valores de erosividade que variam de 6.743,6 e 7.017,9 MJ.mm/ha.h.ano. Logo, afirma-se que em $67,5 \%$ da área estudada predominam as classes de erosividade média a muita alta. Os dados revelam a necessidade de uma exploração humana racional, posto o predomínio de classes de elevada erosividade das chuvas.

Palavras-chave: Variável Climática. Área Suscetível à Desertificação. Geoprocessamento.

\begin{abstract}
The constant human exploration in naturally fragile territories, the example of stretch of the meddle course of the river basin Poti, refers to the need for determining the potential of rainy Erosivity (R). For this, the data of 13 (thirteen) rainfall stations of the oversight of development of northeast (SUDENE) were used. The data had its flaws corrected according to Regional weighting Method, handled and refined via USUAIS programs package. Were identified and specialized 05 (five) classes of Erosivity of rain to the area. Interpretation of the data has shown that the area presents erosivity values ranging from 6,743.6 and 7,017.9 MJ.mm/ha.h.ano. Soon, it says that $67.5 \%$ of the area studied predominate in the classes of erosivity medium to very high. The data reveal the need for a rational human exploration, given the predominance of classes of high erosivity rain.
\end{abstract}

Keywords: Climatic Variable. Area Susceptible to Desertification. Geoprocessing.

\section{INTRODUÇÃO}

O recorrente descaso com o meio ambiente vem tornando os recursos naturais cada vez mais escassos. A exploração dos solos, principalmente para prática da agricultura, converte um solo praticamente protegido por vegetação, em um solo com características vulneráveis à erosão. Tal fato leva a redução da quantidade e qualidade de água nos rios, ao assoreamento dos cursos d'água e ao consequente comprometimento da qualidade de vida das populações; posto todas as atividades humanas demandarem o uso deste recurso para o seu desenvolvimento.

A erosão dos solos nas regiões semiáridas encontra-se acentuada, devido à concentração de chuvas em períodos curtos do ano e ao manejo inadequado das práticas agrícolas, que tornam o solo mais vulnerável e, consequentemente, o processo de erosão ainda mais forte. Dentre as áreas semiáridas, o Nordeste destaca-se como a região mais vulnerável à erosão, quando considerados fatores decisivos como a pluviosidade, a extensão territorial e a densidade populacional (SILVA et al., 2009). 
A afirmativa do autor supracitado ressalta a preocupação com os processos de erosão dos solos, que tem favorecido estudos sobre a Erosividade das chuvas (R) (SOUSA e SILVA, 2009; SANTOS e AQUINO, 2015). Nesse sentido, o presente trabalho objetivou analisar a Erosividade das chuvas (R) no trecho do médio curso da Bacia do rio Poti, área localizada em região semiárida, que apresenta uma cobertura vegetal naturalmente frágil e vulnerável à exploração humana. Estas condições tornam o presente estudo relevante, posto fornecer elementos para análise acerca degradação na região.

Para a efetivação do estudo, foram realizados procedimentos a partir de ferramentas geotecnológicas, possibilitando o manuseio e a correção de erros em dados fundamentais para a realização da pesquisa.

\section{METODOLOGIA}

\subsection{Procedimentos metodológicos}

Para estimativa da Erosividade das chuvas (R) utilizou-se dados de precipitações de 13 (treze) estações pluviométricas da SUDENE (1990), conforme apresentado no Quadro 01, considerando uma série histórica de 1962 a 1985. Os dados em questão foram utilizados de acordo com a proposta metodológica de Thornthwaite e Mather (1955), cujas falhas foram corrigidas conforme Método de Ponderação Regional proposto por Tucci (1993).

Quadro 01. Estações pluviometricas usadas para estimar a Erosividade das chuvas (R) em trecho do médio curso da Bacia Hidrográfica do rio Poti. Fonte: SUDENE (1990).

\begin{tabular}{|c|c|c|c|c|}
\hline Município & Nome do Posto & Lat. & Long. & Alt. (m) \\
\hline Alto Longá & Alto Longá & $05^{\circ} 16^{\prime}$ & $42^{\circ} 13^{\prime}$ & 150 \\
\hline Castelo do Piauí & Castelo do Piauí & $05^{\circ} 20^{\prime}$ & $41^{\circ} 34^{\prime}$ & 250 \\
\hline Castelo do Piauí & Santana & $05^{\circ} 20^{\prime}$ & $41^{\circ} 05^{\prime}$ & 730 \\
\hline Pedro II & Pedro II & $04^{\circ} 25^{\prime}$ & $41^{\circ} 28^{\prime}$ & 580 \\
\hline Pedro II & Madeira Cortada & $04^{\circ} 29^{\prime}$ & $41^{\circ} 10^{\prime}$ & 600 \\
\hline Pedro II & Retiro & $04^{\circ} 40^{\prime}$ & $41^{\circ} 28^{\prime}$ & 530 \\
\hline Pimenteiras & Oitis & $06^{\circ} 22^{\prime}$ & $41^{\circ} 37^{\prime}$ & 270 \\
\hline São João da Serra & São João da Serra & $05^{\circ} 30^{\prime}$ & $41^{\circ} 55^{\prime}$ & 120 \\
\hline São Miguel do Tapuio & Alivio & $05^{\circ} 27^{\prime}$ & $41^{\circ} 06^{\prime}$ & 730 \\
\hline São Miguel do Tapuio & Assunção & $05^{\circ} 52^{\prime}$ & $41^{\circ} 03^{\prime}$ & 480 \\
\hline São Miguel do Tapuio & Dico Leopoldino & $05^{\circ} 51^{\prime}$ & $42^{\circ} 23^{\prime}$ & 290 \\
\hline São Miguel do Tapuio & São Miguel do Tapuio & $05^{\circ} 30^{\prime}$ & $41^{\circ} 20^{\prime}$ & 440 \\
\hline São Miguel do Tapuio & São Vicente & $05^{\circ} 43^{\prime}$ & $41^{\circ} 42^{\prime}$ & 220 \\
\hline
\end{tabular}

Os dados das estações foram manuseados através do pacote de programas USUAIS, conforme proposta metodológica de Oliveira e Sales (2016). Cita-se, ainda, que o pacote de programas foi 
utilizado para correção das falhas e estimativa do fator R. Posteriormente, os dados foram tabelados em planilhas eletrônicas. Os quadros, por sua vez, foram manuseados no QGIS utilizando-se o método de interpolação IDW (peso pelo inverso da distância), na qual foi possível espacializar os dados de Erosividade das chuvas.

O fator R foi estimado mediante a Equação 1, proposta por Lombardi Neto e Moldenhauer (1992), que se baseia em regressão linear entre o índice médio mensal de erosão e o coeficiente de chuva, apresentando relativa precisão em relação aos valores de $\mathrm{R}$ para longos períodos, ao passo que possui boa aceitação entre os pesquisadores brasileiros.

$$
\mathrm{E}=67,355\left(\mathbf{r}^{2} / \mathrm{P}\right)^{0,85}
$$

Onde:

$\mathbf{E}=$ média mensal do índice de erosão (t/ha.mm/h);

$\mathbf{r}=$ precipitação média mensal em mm;

$\mathbf{P}=$ precipitação média anual em $\mathrm{mm}$.

Posteriormente, a partir dos dados das 13 (treze) estações, foram estabelecidas as seguintes classes de Erosividade das chuvas, conforme mostra a Tabela 01. Destaca-se que as classes dos valores do fator $\mathrm{R}$ foram obtidas a partir da subtração do valor máximo pelo valor mínimo encontrado, cujo resultado foi dividido pelo número de classes pretendidas (05 classes).

Tabela 01. Intervalos e classes de Erosividade das chuvas (R). Fonte: Santos (2015). Adaptado por Cerqueira et al. (2016).

\begin{tabular}{cc}
\hline Classes de R $($ MJ.mm/ha.h.ano) & Classe atribuída \\
\hline $6.195<\mathrm{R}<6.469,3$ & Muito Baixa \\
$6.469,3<\mathrm{R}<6.743,6$ & Baixa \\
$6.743,6<\mathrm{R}<7.017,9$ & Média \\
$7.017,9<\mathrm{R}<7.292,2$ & Alta \\
$7.292,2<\mathrm{R}<7.566,7$ & Muito Alta \\
\hline
\end{tabular}

\subsection{Localização da área em estudo}

O estudo foi desenvolvido no trecho do médio curso da Bacia do rio Poti, situado no Território de Desenvolvimento dos Carnaubais (PIAUÍ, 2006). O referido trecho apresenta uma área de aproximadamente $1.466,7 \mathrm{~km}^{2}$, perímetro de $239,1 \mathrm{~km}^{2}$ e situa-se entre os municípios de Juazeiro do Piauí e Castelo do Piauí (Figura 01). 


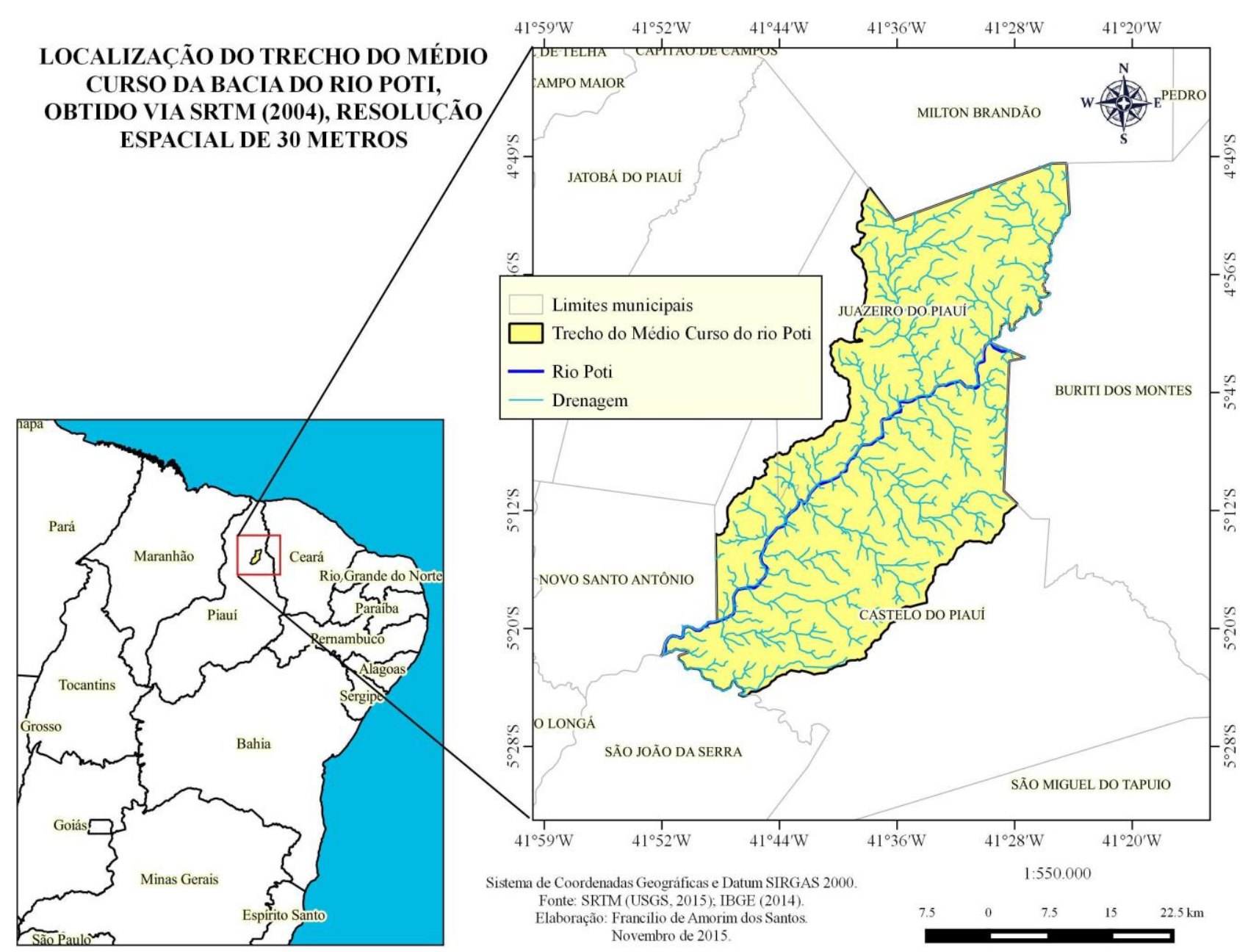

Figura 01. Localização do trecho do médio curso da Bacia do rio Poti, obtido via extração de bacias através de imagens MDE SRTM. Fonte: USGS (2015); IBGE (2010).

\section{RESULTADOS E DISCUSSÃO}

Os dados relativos ao fator Erosividade das chuvas $(\mathrm{R})$ do trecho do médio curso da Bacia do rio Poti revelaram variedade quanto aos níveis de Erosividade, conforme representado na Figura 02. 


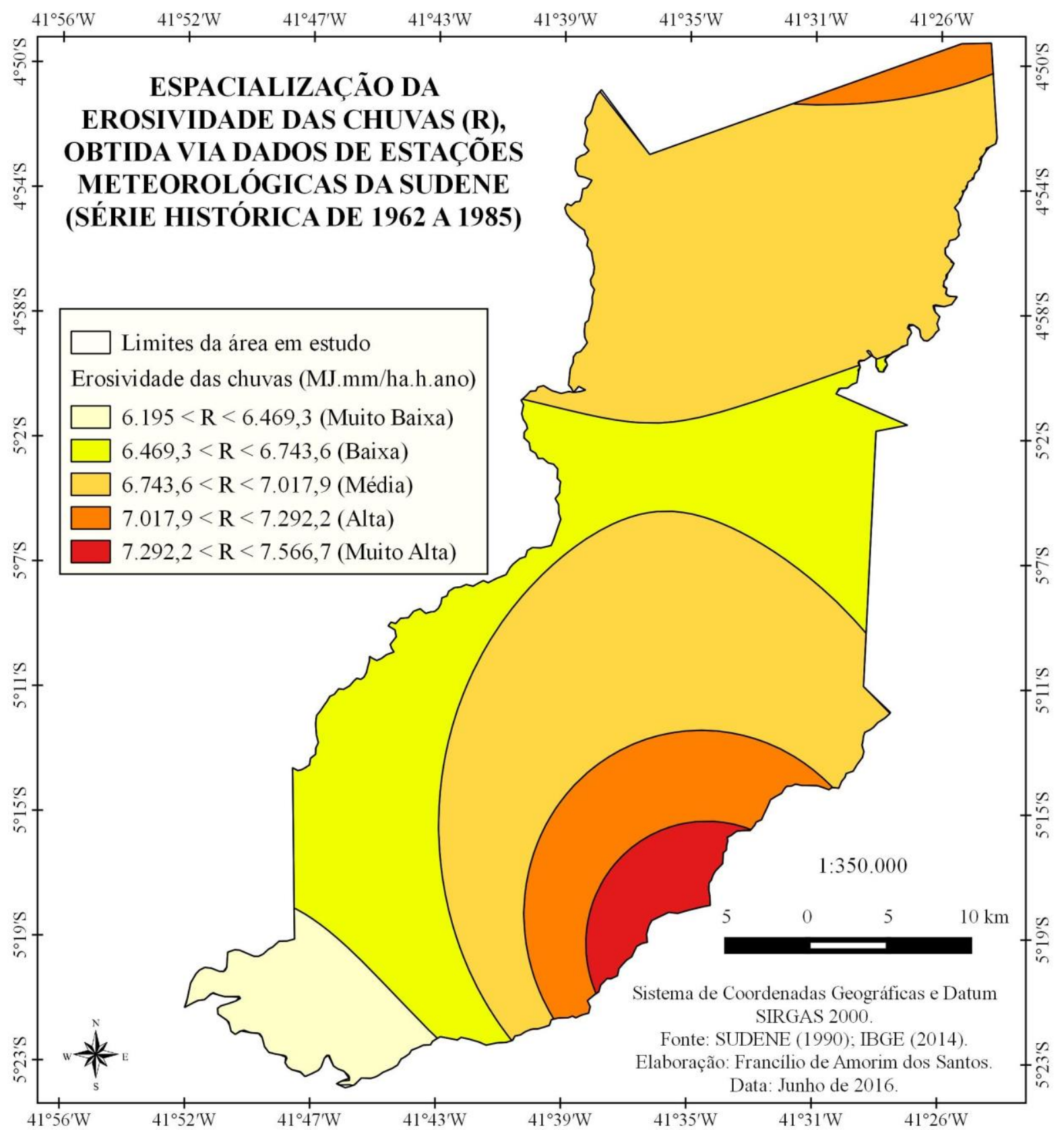

Figura 02. Espacialização da Erosividade das chuvas (R) no trecho do médio curso da Bacia do rio Poti, obtido via dados de precipitação (série histórica de 1962 a 1985) e interpolados no QGIS. Fonte: SUDENE (1990).

Observa-se que na área predominam as classes compreendidas entre baixa e alta. Por sua vez, as classes de Erosividade muito baixa e muito alta restringem-se a pequenas áreas localizadas ao Sul do trecho em estudo.

A partir dos dados da Tabela 02, constata-se que a classe muito baixa de Erosividade ocupa somente 5,6 \% da área total da Bacia. A classe denominada baixa ocupa 26,9\% da área. Ao passo que na maior parte da área predomina a classe de Erosividade média, ocupando 54,5\% da área. Por outro lado, em 9,7\% da área da Bacia a Erosividade foi classificada como alta e em 3,3\% foi classificada como muito alta. 
Tabela 02. Intervalos, classes, área absoluta e relativa de Erosividade das chuvas (R) no trecho do médio curso da Bacia do rio Poti. Fonte: Elaborada pelos autores.

\begin{tabular}{cccc}
\hline Classes de R $(\mathbf{M J} . \mathbf{m m} / \mathbf{h a . h . a n o})$ & Classe atribuída & Área $\left.\mathbf{( k m}^{\mathbf{2}}\right)$ & \% \\
\hline $6.195<\mathrm{R}<6.469,3$ & Muito Baixa & 82,1 & 5,6 \\
$6.469,3<\mathrm{R}<6.743,6$ & Baixa & 394,5 & 26,9 \\
$6.743,6<\mathrm{R}<7.017,9$ & Média & 799,4 & 54,5 \\
$7.017,9<\mathrm{R}<7.292,2$ & Alta & 142,3 & 9,7 \\
$7.292,2<\mathrm{R}<7.566,7$ & Muito Alta & 48,4 & 3,3 \\
\hline Total & - & $\mathbf{1 . 4 6 6 , 7}$ & $\mathbf{1 0 0}$ \\
\hline
\end{tabular}

Os resultados alcançados são análogos aos apresentados em Aquino et al. (2008), que também identificou variações nas classes de Erosividade. Entretanto, os autores constataram ser a classe de baixa Erosividade a predominante nas terras secas do estado do Piauí.

O estudo de Santos e Aquino (2015) apresentou grande semelhança quanto aos índices para o fator R encontrados, determinando também 05 (cinco) classes de Erosividade das chuvas. Porém, a classe muito alta prevaleceu nos municípios de Castelo do Piauí e Juazeiro do Piauí.

\section{CONSIDERAÇÕES FINAIS}

Constatou-se que a área em estudo apresentou valores de Erosividade que variaram de 6.743,6 a 7.017,9 MJ.mm/ha.h.ano, sendo que 32,5\% do trecho do médio curso da Bacia do rio Poti apresentou valores de Erosividade que permitem enquadrá-los nas classes muito baixa e baixa. Ao passo que em $67,5 \%$ da área predominam as classes de Erosividade média, alta e muita alta.

Considerando que a Erosividade revela a capacidade da chuva em causar erosão, o percentual de 67,5\% da área enquadrada como de Erosividade média, alta e muita alta, sugeri que haja um monitoramento acerca das atividades relativas ao uso das terras, posto que a remoção da cobertura vegetal acentuará notadamente os processos de erosão hídrica.

\section{REFERÊNCIAS}

AQUINO, C.M.S; OLIVEIRA, J.G.B; SALES, M.C.L. Estimativa da erosividade das chuvas (R) nas terras secas do Estado do Piaú. Revista Ciência Agronômica, v. 37, n. 3, p. 287-291, 2008.

IBGE - Instituto Brasileiro de Geografia e Estatística. Malha municipal digital do Brasil: situação em 2010. Rio de Janeiro: IBGE, 2012. Disponível em: 〈ftp://geoftp.ibge.gov.br/malhas_digitais/>. Acesso em 27 de agosto de 2015.

LOMBARDI NETO, F.; MOLDENHAUER, W.C. Erosividade da chuva: sua distribuição e relação com perdas de solos em Campinas - SP. Bragantina, Campinas, v. 51, nº 2, p.189-1996, 1992. 
PIAUÍ. Gabinete do Governador. Palácio de Karnak. Projeto de Lei Complementar nº04, de 14 de fevereiro de 2006. Estabelece o Planejamento Participativo Territorial para o Desenvolvimento Sustentável do estado do Piauí e dá outras providências. 2006.

OLIVEIRA, J.G.B.; SALES, M.C.L. Usuais: programas para uso em análise ambiental. Revista Equador (UFPI), Vol. 5, n. 2, p.36-60, Janeiro/Junho, 2016.

SANTOS, F.A. Mapeamento das unidades geoambientais e estudo do risco de degradação/desertificação nos municípios de Castelo do Piauí e Juazeiro do Piauí. Dissertação (Mestrado em Geografia) - Universidade Federal do Piauí. Teresina - PI. 2015.

SANTOS, F.A.; AQUINO, C.M.S. Erosividade das chuvas (R) nos municípios de Castelo do Piauí e Juazeiro do Piauí, no estado do Piauí (BRASIL). Geoambiente On-line, n. 25, 2015.

SILVA, R.M.; PAIVA, F.M.L.; SANTOS, C.A.G. Análise do grau de Erodibilidade e perdas de solo na Bacia do rio Capiá baseado em SIG e sensoriamento remoto. Revista Brasileira de Geografia Física, v. 2, n. 1, p. 26-40, 2009.

SOUSA, F.A.; SILVA, L. Erosividade das chuvas na porção norte da Bacia Hidrográfica do Ribeirão Santo Antônio em Iporá-GO. 2009.

SUDENE. Dados Pluviométricos Mensais do Nordeste: Estado do Piauí. Recife, 1990.

THORNTHWAITE, C.W; MATHER, J.R. The Water Balance - Publications in Climatology. New Jersey: Centerton, v. VIII, $n^{\circ} 1,1955$.

TUCCI, C.E.M. Hidrologia: ciência e aplicação. Porto Alegre: Eds. da UFRGS e da USP, 1993.

USGS - United States Geological Service (Serviço Geológico dos Estados Unidos). Earth Explorer - Digital Elevation - SRTM 1 Arc-Second Global. 2015. Disponível em <http://earthexplorer.usgs.gov/>. Acesso em 23 de novembro de 2015.

Recebido em: 14/08/2016

Aceito para publicação em: 01/10/2016 